\title{
The transcription factors Snail1 and Snail2 repress vitamin D receptor during colon cancer progression
}

\author{
María Jesús Larriba $^{\text {a,* }}$, Félix Bonilla ${ }^{\text {b }}$, Alberto Muñoz ${ }^{a}$ \\ a Instituto de Investigaciones Biomédicas "Alberto Sols", Consejo Superior de Investigaciones Científicas- \\ Universidad Autónoma de Madrid, Arturo Duperier 4, 28029 Madrid, Spain

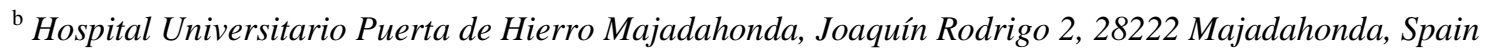 \\ * Corresponding author. Tel.: +34-91-5854452; fax: +34-91-5854401. \\ E-mail address: mjlarriba@iib.uam.es (M.J. Larriba).
}

\begin{abstract}
Vitamin D receptor (VDR) mediates the antitumoral action of the active vitamin D metabolite $1 \alpha, 25$ dihydroxyvitamin $\mathrm{D}_{3}\left(1,25(\mathrm{OH})_{2} \mathrm{D}_{3}\right)$. However, VDR expression is lost during colon cancer progression, possibly causing unresponsiveness to $1,25(\mathrm{OH})_{2} \mathrm{D}_{3}$. Although several mechanisms responsible for resistance to $1,25(\mathrm{OH})_{2} \mathrm{D}_{3}$ action in different types of cancer had been reported, none explained the loss of VDR expression. We have found that the transcription factors Snail1 and Snail2, known as inducers of epithelial-tomesenchymal transition (EMT), inhibit VDR expression and block $1,25(\mathrm{OH})_{2} \mathrm{D}_{3}$ action in colon cancer cells. Snail1 and Snail2 have an additive repressing effect on $V D R$ gene promoter. These effects are specific to the Snail family, as other transcriptions factors that function as EMT inducers do not inhibit VDR expression in colon cancer cells. Moreover, we also found that the RNA expression of SNAII and SNAI2 are upregulated in human colorectal tumors and inversely correlate with that of VDR. Our results suggest that high levels of SNAIL1 and SNAIL2 are a probable cause of VDR downregulation and $1,25(\mathrm{OH})_{2} \mathrm{D}_{3}$ unresponsiveness in colon cancer. In addition, they may contribute to the improvement of protocols for the clinical use of vitamin D compounds, as they indicate that advanced colon cancer patients overexpressing SNAIL1 and SNAIL2 are not suitable candidates for this therapy.
\end{abstract}

Keywords: Snail1; Snail2; vitamin D receptor; $1 \alpha, 25$-dihydroxyvitamin $\mathrm{D}_{3}$; colon cancer Abbreviations: EMT, epithelial-to-mesenchymal transition; VDR, vitamin D receptor; $1,25(\mathrm{OH})_{2} \mathrm{D}_{3}, 1 \alpha, 25-$ dihydroxyvitamin $\mathrm{D}_{3}$ 


\section{Introduction}

1 $\alpha, 25$-dihydroxyvitamin $\mathrm{D}_{3}\left(1,25(\mathrm{OH})_{2} \mathrm{D}_{3}\right)$ and a number of less calcemic analogs are in clinical trials as anticancer agents against colon cancer and other neoplasias based on their antiproliferative, prodifferentiation, pro-apoptotic and antimetastatic activity in cultured cells and experimental animal models [1,2]. We have shown that $1,25(\mathrm{OH})_{2} \mathrm{D}_{3}$ inhibits proliferation and promotes differentiation of human colon cancer cells via the induction of several genes such the invasion suppressor $C D H 1 / \mathrm{E}$-cadherin and the candidate tumor suppressor CST5/cystatin D, and by the antagonism of the $\mathrm{Wnt} / \beta$-catenin pathway that is aberrantly activated in most colon tumors [3-5]

Although preclinical studies are promising, initial clinical trials in colon cancer have shown acceptable toxicity but low activity of vitamin D compounds [1]. As is usual in the development of new antitumoral drugs, patients enrolled in these trials had not responded to any other therapy and they were unselected in terms of putative responsiveness to $1,25(\mathrm{OH})_{2} \mathrm{D}_{3}$. A better understanding of the physiology of the vitamin $\mathrm{D}$ system and the identification of the mechanisms responsible for resistance to $1,25(\mathrm{OH})_{2} \mathrm{D}_{3}$ may help us to design future clinical trials more rationally.

\section{Vitamin D receptor is downregulated during colon cancer progression}

Most, if not all, $1,25(\mathrm{OH})_{2} \mathrm{D}_{3}$ effects are mediated by the vitamin $\mathrm{D}$ receptor (VDR), a transcription factor of the nuclear receptor superfamily. Thus, cellular VDR expression is required for a clinical response to vitamin D compounds. VDR is expressed in normal colon epithelial cells and also in some colon cancer cells. Remarkably, elevated VDR expression is associated with high differentiation, absence of node involvement and favourable prognosis in colorectal cancer [6,7]. However, VDR expression is downregulated during colon cancer progression [8-10] probably causing $1,25(\mathrm{OH})_{2} \mathrm{D}_{3}$ unresponsiveness.

Although VDR downregulation in colon cancer was first described more than a decade ago, its molecular basis had remained elusive. Deletions, rearrangements or point mutations affecting the coding region of the $V D R$ gene had not been found in cancer. Neither had epigenetic silencing or transcriptional repression mechanisms been described. Several polymorphisms had been described in the VDR gene, some of which have been associated with increased risk of breast, prostate and colon cancer. However, their consequences for VDR expression or functionality, and therefore their implication in the development of $1,25(\mathrm{OH})_{2} \mathrm{D}_{3}$ resistance remain to be established $[11,12]$. 


\section{The transcription factors Snail1 and Snail2 repress VDR expression in colon cancer cells}

A novel mechanism responsible for VDR downregulation in colon cancer has emerged in recent years. Our group has revealed that the transcription factors Snail1 and Snail2 (also known as Snail and Slug) encoded by Snail and Snai2 genes, respectively, bind to the promoter region of exon 1a of human VDR gene and repress its expression. The repressive effects of Snail1 and Snail2 on VDR gene promoter are quantitatively similar and are mediated by three E-boxes (CAGGTG/CACCTG, reported binding sites for Snail factors) present in the first 400 nucleotides of human VDR promoter. In addition, we found that both transcription factors cooperate to repress VDR promoter, showing an additive effect $[13,14]$.

We also found that the overexpression (by means of retrovirus-mediated gene transfer) of Snail1 or Snail2 in human colon cancer cells decreases VDR RNA and protein expression and strongly inhibits the regulation of $1,25(\mathrm{OH})_{2} \mathrm{D}_{3}$ target genes such as $C D H 1 / \mathrm{E}$-cadherin, ${ }^{2} 1^{C I P 1}$ and $C Y P 24 A 1 / 1,25(\mathrm{OH})_{2} \mathrm{D}_{3}$-24-hydroxylase. Accordingly, Snail transcription factors block the epithelial differentiation induced by $1,25(\mathrm{OH})_{2} \mathrm{D}_{3}$ in colon cancer cells (Fig. 1) and also the inhibitory effect of $1,25(\mathrm{OH})_{2} \mathrm{D}_{3}$ on Wnt/ $/$-catenin signaling pathway [13-15].

\section{Relevance of VDR downregulation for the epithelial-to-mesenchymal transition induced by Snail1 and} Snail2

Snail1 and Snail2 belong to the Snail family of zinc-finger transcription factors and modulate processes that imply cell movement during embryonic development and tumor progression. Cellular overexpression of Snail1 or Snail2 induces the epithelial-to-mesenchymal transition (EMT), which entails the loss of epithelial characteristics and the acquisition of a mesenchymal fibroblastic phenotype [16,17]. Therefore, the expression of Snail1 or Snail2 in carcinoma cells promotes their migratory and invasive properties favoring tumor invasion and metastasis. Accordingly, the aberrant overexpression of SNAIL1 and/or SNAIL2 has been observed in different types of carcinomas and is frequently associated with invasiveness, metastasis and poor prognosis $[16,17]$.

EMT induction is not an exclusive effect of Snail factors. Other transcriptional regulators such as E47, Twist1 and E2-2 (members of the basic-helix-loop-helix family), and Zeb1 and Zeb2 (of the Zeb family) also promote this process. EMT is mainly the result of transcriptional changes induced by these factors such as the repression of $C D H 1 / E-c a d h e r i n, O C L N / o c c l u d i n$, several claudins and other epithelial genes and the induction of mesenchymal genes such as $F N 1 /$ fibronectin, VIM/vimentin, $L E F 1$ and numerous matrix metalloproteases $[16,17]$ 
As ligand-activated VDR induces epithelial differentiation and the expression of $\mathrm{CDHI/E-cadherin} \mathrm{and}$ other intercellular adhesion genes, VDR repression by Snail1 and Snail2 guarantees the induction of EMT even in the presence of $1,25(\mathrm{OH})_{2} \mathrm{D}_{3}$. This effect seems to be specific to the Snail family of transcription factors, since other EMT inducers such as Zeb1, Zeb2, E47 and Twist1 do not inhibit human VDR gene promoter [14].

\section{Snail1 and Snail2 are responsible for VDR downregulation in colon cancer}

To confirm the importance of Snail transcription factors in VDR downregulation during colon cancer progression, we analyzed SNAII, SNAI2 and VDR RNA expression in normal and tumoral biopsies from approximately one hundred colon cancer patients. We found that SNAII RNA was not present in any normal colonic tissue but it was expressed in $60-70 \%$ (depending on the study) of colon tumors. VDR expression in tumors was reduced with respect to that detected in the corresponding normal tissue in a similar percentage of tumors. In contrast, basal SNAI2 RNA expression was detected in most normal tissues and was also upregulated in $60 \%$ of colon tumors. Importantly, we observed that the overexpression of either SNAII or SNAI2 in individual tumors correlates with VDR downregulation $[13,14,18,19]$. In addition, we found that SNAII and SNAI2 RNA expression correlate directly and, therefore, a high percentage of tumors (42\%) express both transcription factors. Remarkably, VDR downregulation was stronger in the tumors that express both SNAII and SNAI2 than in those that express only one of these genes. This is consistent with the additive effect exerted by Snail1 and Snail2 on VDR gene promoter in cultured human colon cancer cells [14]. Therefore, it seems that Snail1 and Snail2 collaborate in the repression of $V D R$ gene in human colon cancer.

Based on the hypothesis that tumors cells can influence adjacent normal cells and that some genetic alterations occur before the development of histologically abnormal tissue, we have recently expanded our studies to analyze the effect of tumoral SNAII overexpression on the levels of VDR in the histologically normal colonic tissue adjacent to the tumor. We have found that tumoral SNAII overexpression correlates with VDR downregulation both in the tumor and in the normal adjacent tissue, indicating that SNAIL1 induce the release of paracrine signals from the tumoral cells that affect adjacent normal cells [20]. This could extend the unresponsiveness to vitamin D compounds to the normal tissue surrounding the tumor.

The repression of VDR by Snail transcription factors is not exclusive to colon cancer, as it has also been observed in human breast cancer cells (ref. 21 and unpublished results). Also, Snail1 inhibits VDR expression in mouse osteoblasts [22]. As SNAIL1 and/or SNAIL2 upregulation has been reported in several types of 
cancer [16], this mechanism could explain the resistance to $1,25(\mathrm{OH})_{2} \mathrm{D}_{3}$ action due to the VDR repression found in other types of tumors [10].

\section{Conclusion}

Our studies indicate that the transcription factors Snail1 and Snail2 are repressors of VDR and thus of $1,25(\mathrm{OH})_{2} \mathrm{D}_{3}$ action in colon cancer cells (Fig. 2). Data from colon cancer biopsies indicate that SNAIL1 and SNAIL2 may be responsible for VDR downregulation during colon cancer progression.

Colon cancer patients with high levels of SNAIL1 and SNAIL2 have lower VDR expression and, therefore, will be resistant to a therapy with vitamin D compounds. Thus, tumor expression of SNAIL1 and SNAIL2 may be used as an indicator of patient adequacy to this treatment. Several groups have detected tumorassociated RNA in the serum/plasma of cancer patients [23]. If tumor overexpression of SNAII and SNAI2 could be monitored by RT-PCR analysis of the RNA present in the serum/plasma, it would constitute a noninvasive method to select suitable patients for therapy with vitamin D compounds.

\section{Acknowledgements}

We thank Toffa Evans and Robin Rycroft for their help with the English manuscript. The work in authors' laboratories is supported by the Ministerio de Ciencia e Innovación of Spain (SAF2007-60341, ISCIII-RETIC RD06/0020/0009 and RD06/0020/0020), Comunidad de Madrid (S-GEN-0266/2006) and European Union (MRTN-CT-2005-019496, NucSys).

\section{References}

[1] K.K. Deeb, D.L. Trump, C.S. Johnson, Vitamin D signalling pathways in cancer: potential for anticancer therapeutics, Nat. Rev. Cancer 7 (2007) 684-700.

[2] G. Eelen, C. Gysemans, L. Verlinden, E. Vanoirbeek, P. De Clercq, D. Van Haver, C. Mathieu, R. Bouillon, A. Verstuyf, Mechanism and potential of the growth-inhibitory actions of vitamin D and analogs, Curr. Med. Chem. 14 (2007) 1893-1910.

[3] H.G. Pálmer, J.M. González-Sancho, J. Espada, M.T. Berciano, I. Puig, J. Baulida, M. Quintanilla, A. Cano, A. García de Herreros, M. Lafarga, A. Muñoz, Vitamin $\mathrm{D}_{3}$ promotes the differentiation of colon carcinoma cells by the induction of E-cadherin and the inhibition of $\beta$-catenin signaling, J. Cell Biol. 154 (2001) 369-387. 
[4] H.G. Pálmer, M. Sánchez-Carbayo, P. Ordóñez-Morán, M.J. Larriba, C. Cordón-Cardó, A. Muñoz, Genetic signatures of differentiation induced by $1 \alpha, 25$-dihydroxyvitamin $\mathrm{D}_{3}$ in human colon cancer cells, Cancer Res. 63 (2003) 7799-7806.

[5] S. Álvarez-Díaz, N. Valle, J.M. García, C. Peña, J.M. Freije, V. Quesada, A. Astudillo, F. Bonilla, C. López-Otín, A. Muñoz, Cystatin D is a candidate tumor suppressor gene induced by vitamin D in human colon cancer cells, J. Clin. Invest. 119 (2009) 2343-2358.

[6] H.S. Cross, E. Bajna, G. Bises, D. Genser, E. Kállay, R. Pötzi, E. Wenzl, F. Wrba, R. Roka, M. Peterlik, Vitamin D receptor and cytokeratin expression may be progression indicators in human colon cancer, Anticancer Res. 16 (1996) 2333-2337.

[7] S.R.T. Evans, J. Nolla, J. Hanfelt, M. Shabahang, R.J. Nauta, I.B. Shchepotin, Vitamin D receptor expression as a predictive marker of biological behavior in human colorectal cancer, Clin. Cancer Res. 4 (1998) 1591-1595.

[8] H.S. Cross, E. Kállay, M. Khorchide, D. Lechner, Regulation of extrarenal synthesis of 1,25dihydroxyvitamin $\mathrm{D}_{3}$-relevance for colonic cancer prevention and therapy, Mol. Aspects Med. 24 (2003) $459-465$

[9] D. Matusiak, G. Murillo, R.E. Carroll, R.G. Mehta, R.V. Benya, Expression of vitamin D receptor and 25 hydroxyvitamin D3-1 $\alpha$-hydroxylase in normal and malignant human colon, Cancer Epidemiol. Biomarkers Prev. 14 (2005) 2370-2376.

[10] M.G. Anderson, M. Nakane, X. Ruan, P.E. Kroeger, J.R. Wu-Wong, Expression of VDR and CYP24A1 mRNA in human tumors, Cancer Chemother. Pharmacol. 57 (2006) 234-240.

[11] M.J. Campbell, L. Adorini, The vitamin D receptor as a therapeutic target, Expert Opin. Ther. Targets 10 (2006) 735-748.

[12] K. Köstner, N. Denzer, C.S.L. Müller, R. Klein, W. Tilgen, J. Reichrath, The relevance of vitamin D receptor (VDR) gene polymorphisms for cancer: a review of the literature, Anticancer Res. 29 (2009) $3511-3536$

[13] H.G. Pálmer, M.J. Larriba, J.M. García, P. Ordónez-Morán, C. Peña, S. Peiró, I. Puig, R. Rodríguez, R. de la Fuente, A. Bernad, M. Pollán, F. Bonilla, C. Gamallo, A. García de Herreros, A. Muñoz, The transcription factor SNAIL represses vitamin D receptor expression and responsiveness in human colon cancer, Nat. Med. 10 (2004) 917-919. 
[14] M.J. Larriba, E. Martín-Villar, J.M. García, F. Pereira, C. Peña, A. García de Herreros, F. Bonilla, A. Muñoz, Snail2 cooperates with Snail1 in the repression of vitamin D receptor in colon cancer, Carcinogenesis 30 (2009) 1459-1468.

[15] M.J. Larriba, N. Valle, H.G. Pálmer, P. Ordóñez-Morán, S. Álvarez-Díaz, K.F. Becker, C. Gamallo, A. García de Herreros, J.M. González-Sancho, A. Muñoz, The inhibition of Wnt/beta-catenin signalling by 1alpha,25-dihydroxyvitamin D3 is abrogated by Snail1 in human colon cancer cells, Endocr. Relat. Cancer 14 (2007) 141-151.

[16] H. Peinado, D. Olmeda, A. Cano, Snail, Zeb and bHLH factors in tumour progression: an alliance against the epithelial phenotype?, Nat. Rev. Cancer 7 (2007) 415-428.

[17] R. Kalluri, R.A. Weinberg, The basics of epithelial-mesenchymal transition, J. Clin. Invest. 119 (2009) 1420-1428.

[18] C. Peña, J.M. García, J. Silva, V. García, R. Rodríguez, I. Alonso, I. Millán, C. Salas, A. García de Herreros, A. Muñoz, F. Bonilla, E-cadherin and vitamin D receptor regulation by SNAIL and ZEB1 in colon cancer: clinicopathological correlations, Hum. Mol. Genet. 14 (2005) 3361-3370.

[19] C. Peña, J.M. García, V. García, J. Silva, G. Domínguez, R. Rodríguez, C. Maximiano, A. García de Herreros, A. Muñoz, F. Bonilla, The expression levels of the transcriptional regulators p300 and CtBP modulate the correlations between SNAIL, ZEB1, E-cadherin and vitamin D receptor in human colon carcinomas, Int. J. Cancer 119 (2006) 2098-2104.

[20] C. Peña, J.M. García, M.J. Larriba, R. Barderas, I. Gómez, V. García, J. Silva, G. Domínguez, R. Rodríguez, J. Cuevas, A. García de Herreros, J.I. Casal, A. Muñoz, F. Bonilla, SNAI1 expression in colon cancer related with $C D H 1$ and $V D R$ downregulation in normal adjacent tissue, Oncogene, in press.

[21] M.K. Mittal, J.N. Myers, S. Misra, C.K. Bailey, G. Chaudhuri, In vivo binding to and functional repression of the VDR gene promoter by SLUG in human breast cells, Biochem. Biophys. Res. Commun. 372 (2008) 30-34.

[22] C.A. de Frutos, R. Dacquin, S. Vega, P. Jurdic, I. Machuca-Gayet, M.A. Nieto, Snaill controls bone mass by regulating Runx2 and VDR expression during osteoblast differentiation, Embo J. 28 (2009) 686-696.

[23] J.C.H. Tsang, Y.M.D. Lo, Circulating nucleic acids in plasma/serum, Pathology 39 (2007) 197-207. 


\section{Figure Captions}

Fig. 1. The overexpression of Snaill or Snail2 blocks the acquisition of the epithelial differentiated phenotype induced by $1,25(\mathrm{OH})_{2} \mathrm{D}_{3}$ in SW480-ADH human colon cancer cells. Representative phase-contrast images (upper panels) and confocal laser immunofluorescence images showing $\beta$-tubulin staining (lower panels) of

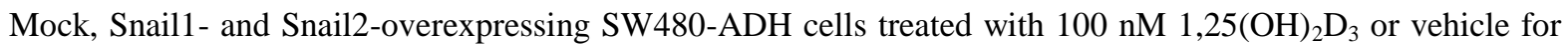
48 h. Scale bar, $25 \mu \mathrm{m}$ (upper panels) and $10 \mu \mathrm{m}$ (lower panels).

Fig. 2. Scheme showing the repression of VDR and thereby of $1,25(\mathrm{OH})_{2} \mathrm{D}_{3}$ action during the EMT induced by Snail1 or Snail2. Normal colon epithelial cells express VDR and are responsive to $1,25(\mathrm{OH})_{2} \mathrm{D}_{3}$ target genes induction and antitumoral activity. Snail1 and/or Snail2 overexpression induce EMT through the regulation of several target genes. Among them, Snail factors bind to three E-boxes present in human VDR gene promoter and inhibit its expression, thus blocking $1,25(\mathrm{OH})_{2} \mathrm{D}_{3}$ action. 
SW480-ADH

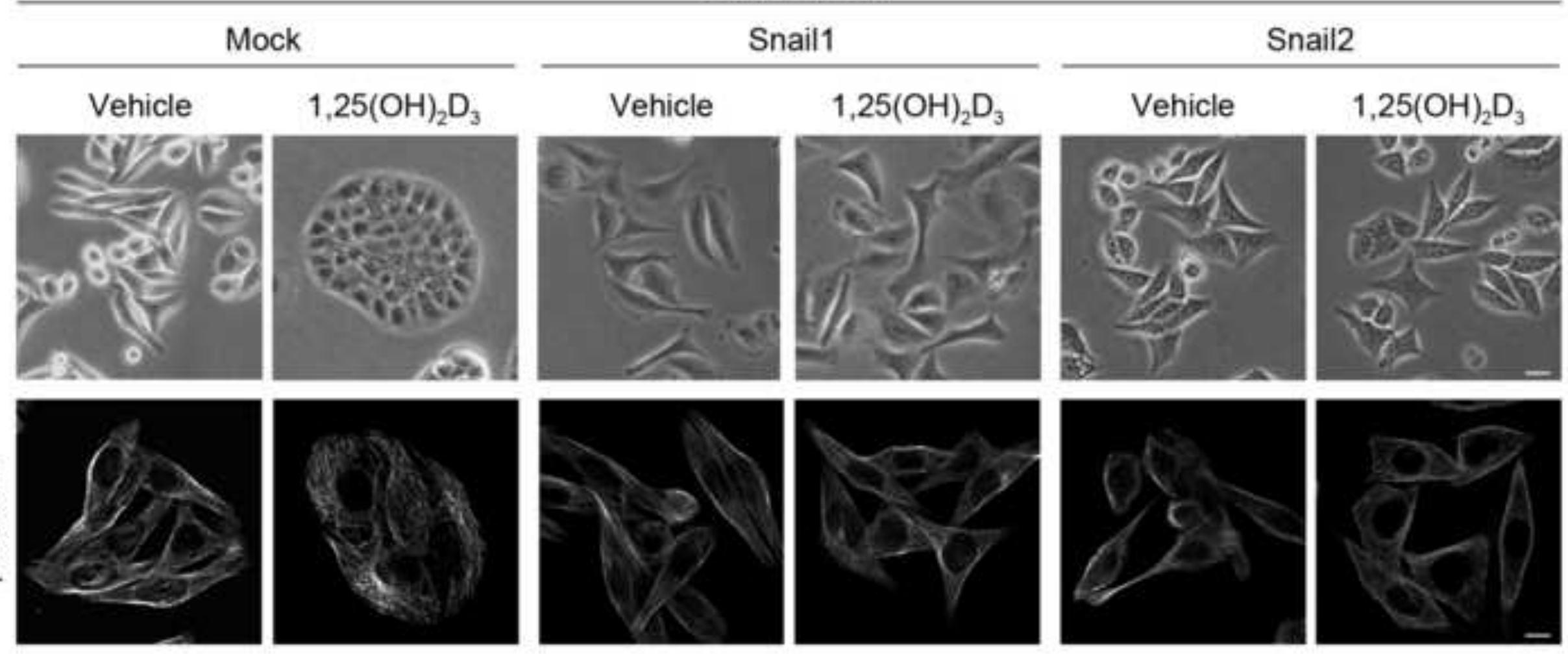
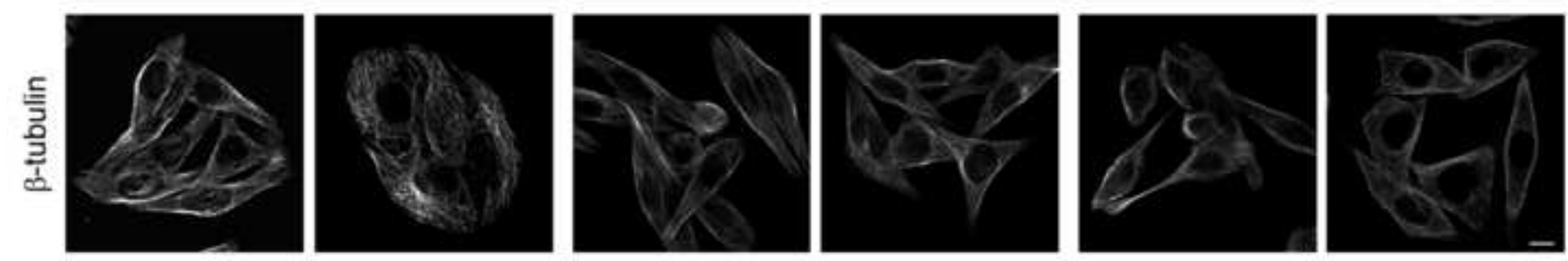


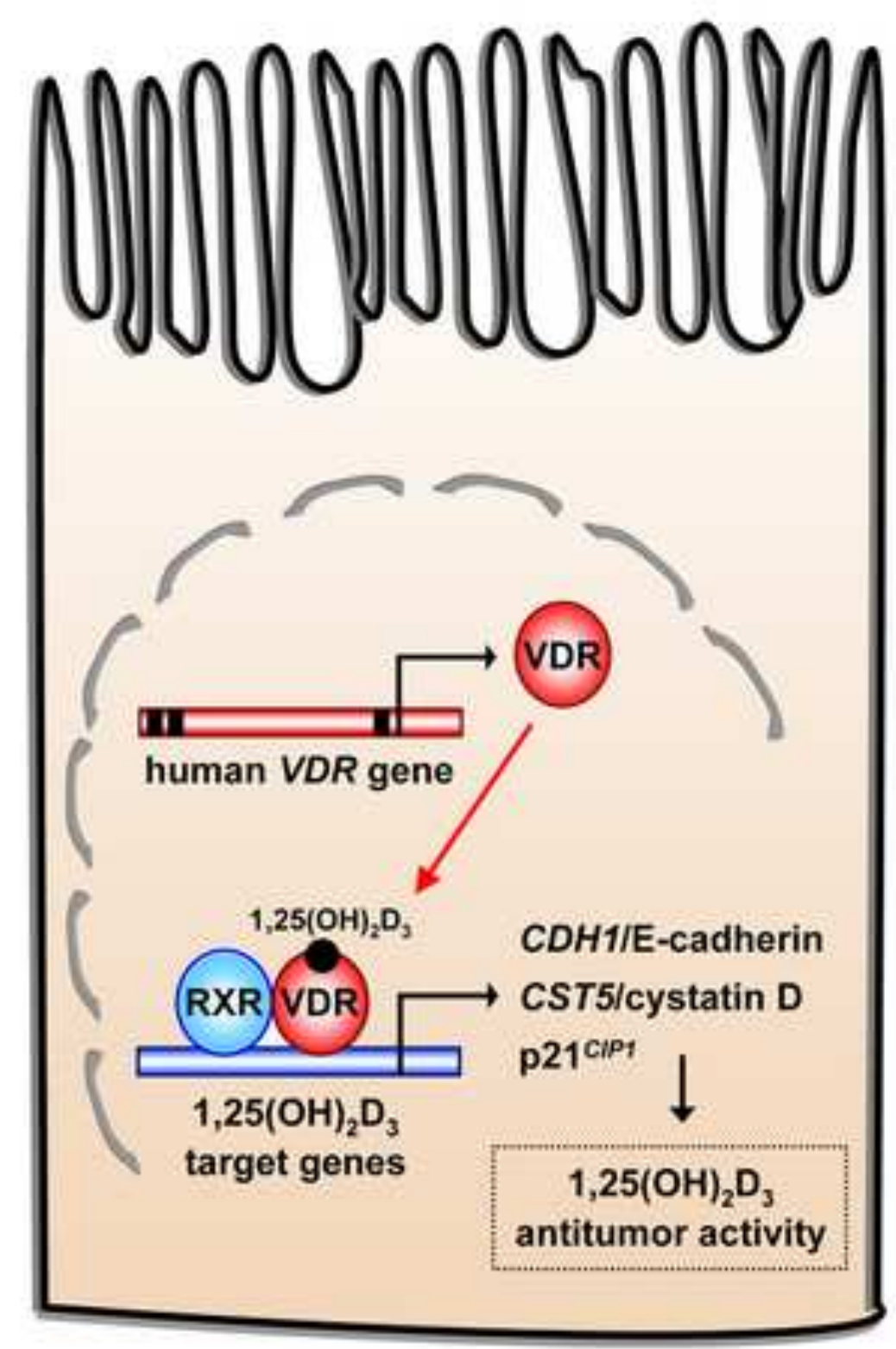

EPITHELIAL CELL

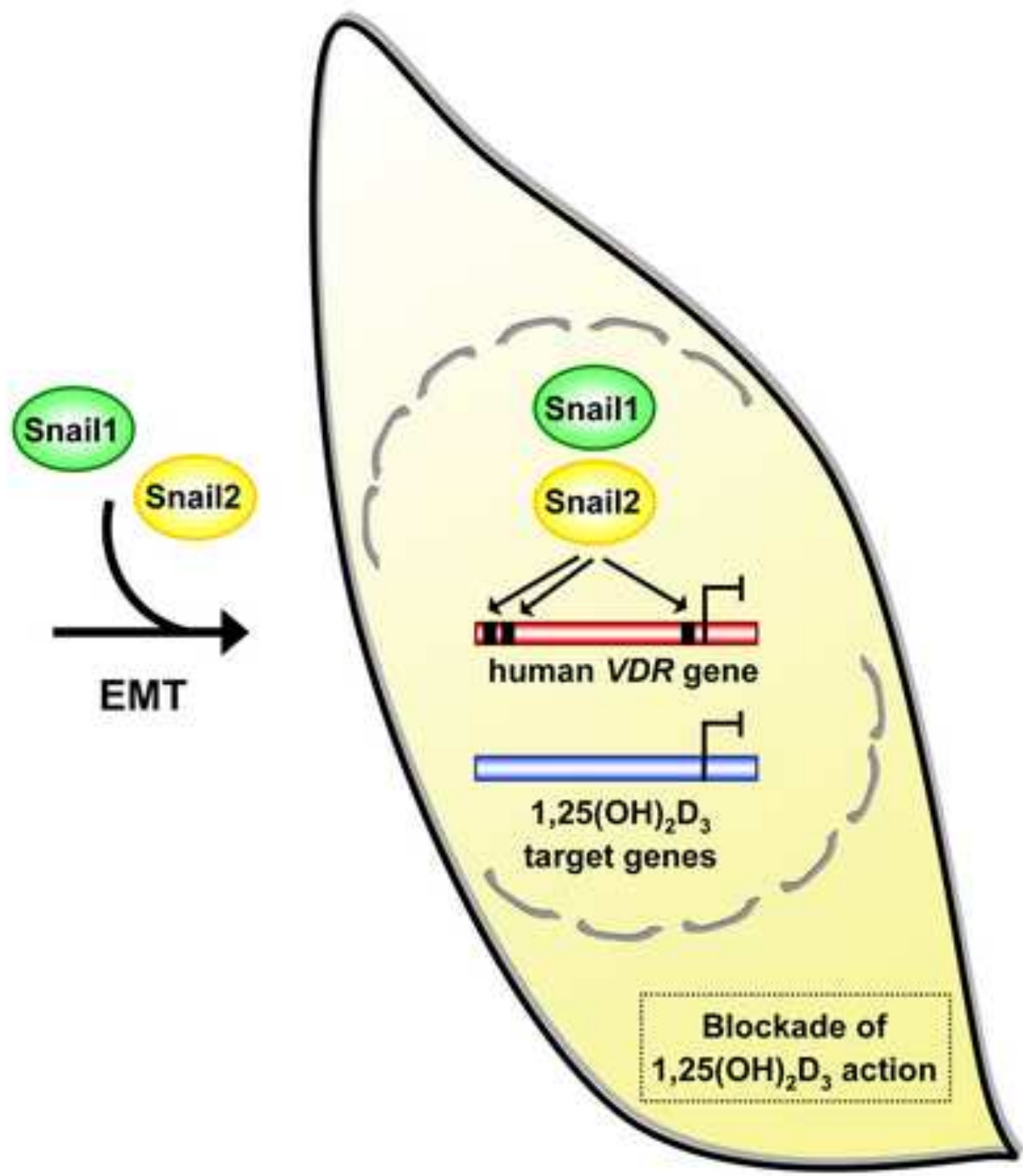

MESENCHYMAL CELL 